Sung-Soo Kim

Jong-Hyun Lee

Soon-Sup Lee

Donghoon Kang

Seung Jae Lee

http://dx.doi.org/10.21278/brod69203

ISSN 0007-215X

eISSN 1845-5859

\title{
A STUDY OF MOTION CHARACTERISTICS LED BY CONNECTION METHODS AND POSITIONS OF A WAVE-ENERGY CONVERTER IN A REGULAR WAVE
}

UDC 629.5.04:629.5.017.26:629.5.04:621.22:621.311:519.6:

Original scientific paper

\begin{abstract}
Summary
The potential of wave power as an alternative energy resource is being studied to address problems associated with fossil fuel exhaustion and environmental pollution. In this paper, to improve the power generation efficiency of a floating-type wave-energy converter that has an activating body, the effects of the positions of a connecting bridge and different connecting methods between a main body and the activating body of the wave-energy converter were studied. In order to research the activating body's motion characteristics that are caused by the changes of connecting bridge's position and connecting methods; hinged or fixed connector, the wave-energy converter was modeled and simulated by using a commercial software. The moment and angular velocity of the axis of power generation were measured from the results of simulations and then the power outputs were calculated based on the moment and angular velocity. The outputs, which were analyzed under several regular wave conditions, were compared to each other.
\end{abstract}

Key words: $\quad$ Wave energy converter; Regular wave; Activating body; Power generation;

\section{Introduction}

Wave power has recently been added to the list of new and renewable energies, such as wind, solar, tidal, and hydropower, to solve the problems of fossil fuel exhaustion and environmental pollution attributed to fossil fuels. Many researchers have tried to develop and improve technologies, such as wave energy converters with a piston or flapper, to convert wave energy $[1,2]$. In general, there are three stages of conversion of wave power generation. The first is primary conversion, which converts the potential energy and kinetic energy generated by the periodic motions of waves into dynamic pressure heads or mechanical motions; the second is secondary conversion, which converts the dynamic pressure heads or mechanical motion into energy for power generation; and the third is the conversion of the 
power produced by the power generator [3]. According to the conversion methods, waveenergy converters can be divided into oscillating water chamber (OWC) types [4], over topping device (OTD) types [5], and wave-activating body (WAB) types [6]. Of these wavepower generation methods, the WAB types have the highest generation efficiency. This is because this type's wave-power generations convert the kinetic energy and potential energy of waves into mechanical motions without any steps. In contrast, OWC types use the airflow in water chamber or water tanks caused by sea surface motion to produce kinetic energy, which is then converted to mechanical motion. OTD types use differences of the dynamic pressure head between average sea surfaces and stored water above structure that overflow the OTD structure. In WAB type wave-energy converters, relative motions between the activating body and the main body of the converter lead to power generation. Thus, the shape of the activating body and the methods used to connect the main body and the activating body are important to enhance the efficiency of power generation [7].

It is evident that the places where are deep-sea regions or have higher waves is suitable to install a wave-energy converter because these areas have much larger wave energy than other common places[8]. However, since installing a wave-energy converter in these suitable places requires awful lot of money, to reduce an installation expense, floating-type converters are usually applied rather than fixed-type converters. In this study, the floating-type was applied. Furthermore, the position of a connecting bridge and the methods used to connect the connecting bridge to an activating body were studied to improve the power generation efficiency of a floating-type wave-energy converter. The power generation efficiency does not include efficiency derived from a generator. Instead, it was focused that mechanical efficiency caused by the position and methods of connecting bridge. To be specific, as the relative motion, which is affected by hydrodynamic interaction of floating structures[9], between the activating body and the main body mainly governs the efficiency of power generation, two factors, which affect the relative motion, were investigated; the positions of connecting bridge located on activating body, and the connecting methods between the connecting bridge and activating body(i.e., hinged or fixed). Simulations were used to compare and analyze the power output, moments, and angular velocities to understand the effects of two factors. In general, many studies have studied a new energy converter design, which has a distinctive converting mechanism[10], or case study of an energy converter: arrays of energy converters, or install areas of converters but there are few studies related to the connection methods and positions. Therefore, the main purpose of this paper is not to suggest a new model that has higher generation efficiency than a previous model but to find out the facts that how the connection methods and positions influence the generation efficiency of the floating-type wave-energy converter. The facts expected to be utilized as a basic data of a wave energy converter. Thus, a simple configuration and single wave direction, which turns towards the front of the floating-type wave-energy converter, was used.

\section{WAB-type wave-energy converter}

\subsection{Basic shape}

The concept of design of the wave-energy converter used in the present study is shown in Figure 1, and the principal dimensions and mass property of the main body and activating body of the wave-energy converter are shown in Table 1 . The wave-energy converter is made up of a main body which generates the power, an activating body, and a connecting bridge. The simple design of wave-energy converter was selected to focus on comparison between two methods of connecting bridge. The H-shaped body type of the main body was chosen to easily set mooring system and to get better stability. A centroid of gravity of the box type activating body was moved down to improve the stability of activating body. An optimization 
process for the shapes of both bodies was not carried out but remain for a next step of research. Although the main body and the activating body are close, there is enough space, which are $1.25 \mathrm{~m}$ in each breadth direction and $1.25 \mathrm{~m}$ in length direction, between them. When incident waves cause heave and pitch motions of the activating body, the resultant kinetic energy is transferred to Joint 1 on the main body as mechanical rotational energy through Joints 2 and 3 on the connecting bridges. This mechanical rotational energy is used to generate power.

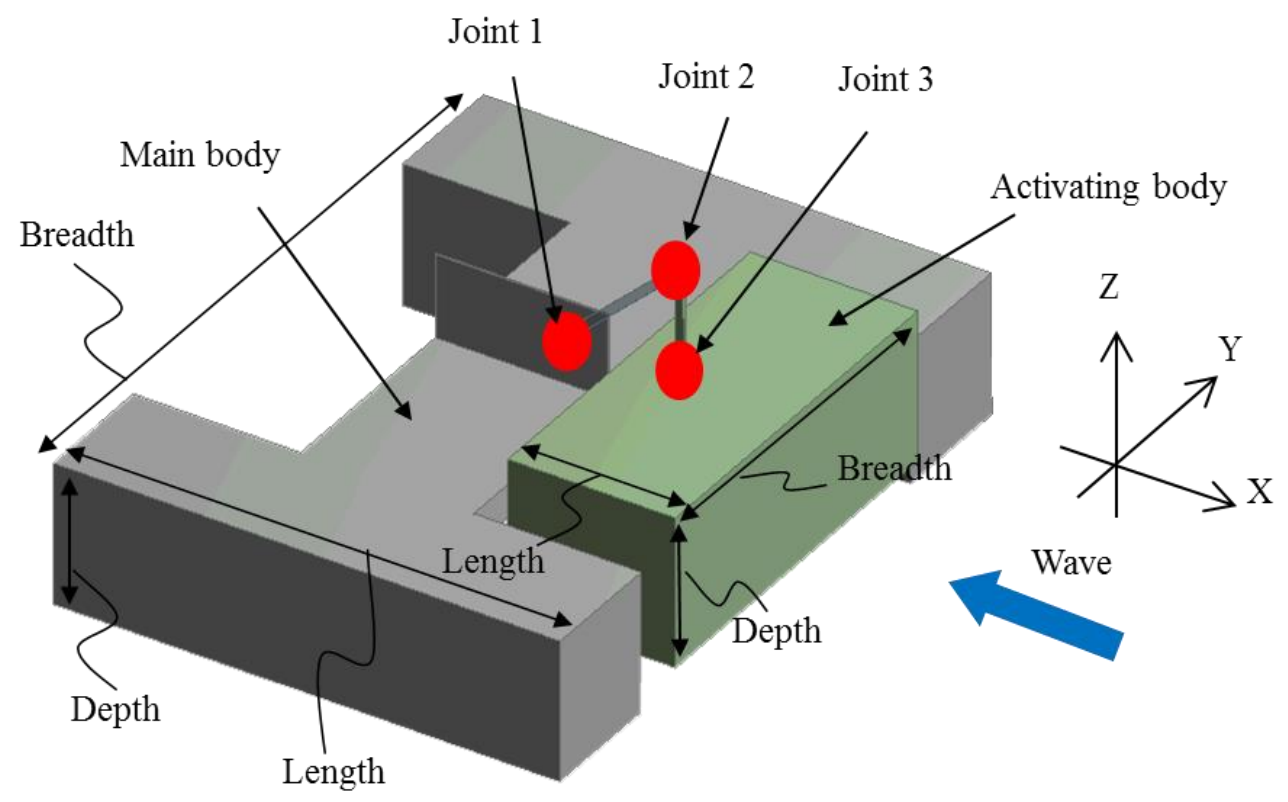

Fig. 1 Conceptive design of the wave-energy converter

Table 1 Principal particulars of the floating type wave-energy converter

\begin{tabular}{|c|c|c|c|}
\hline Factor & Main body & Activating body & Unit \\
\hline Length & 30.35 & 10.00 & $\mathrm{~m}$ \\
\hline Breadth & 40.00 & 22.50 & $\mathrm{~m}$ \\
\hline Depth & 8.50 & 9.00 & $\mathrm{~m}$ \\
\hline Draft & 8.50 & 5.00 & $\mathrm{~m}$ \\
\hline Mass & $3,459.30$ & $1,153.10$ & ton \\
\hline $\begin{array}{c}\text { Radius of gyration } \\
\text { about X axis }\left(k_{x x}\right)\end{array}$ & 23.25 & 6.57 & $\mathrm{~m}$ \\
\hline $\begin{array}{c}\text { Radius of gyration } \\
\text { about Y axis }\left(k_{y y}\right)\end{array}$ & 12.77 & 3.06 & $\mathrm{~m}$ \\
\hline $\begin{array}{c}\text { Radius of gyration } \\
\text { about Z axis }\left(k_{z z}\right)\end{array}$ & 26.01 & 7.11 & $\mathrm{~m}$ \\
\hline
\end{tabular}


The hydrostatic results of main body and activating body are shown in Table 2, which consists of center of gravity, center of buoyancy, $\mathrm{GM}_{\mathrm{T}}$ : Transversal metacentric height, and $\mathrm{GM}_{\mathrm{L}}$ : Longitudinal metacentric height. To support these values, global axis and two local axis of simulations are shown in Figure 2. A left figure of the figure 2 shows the global axis that is a basic coordinate system for the simulation, and a right figure displays both the main body's local axis and the activating body's local axis. The local axis are based on a centroid of gravity of each structures.

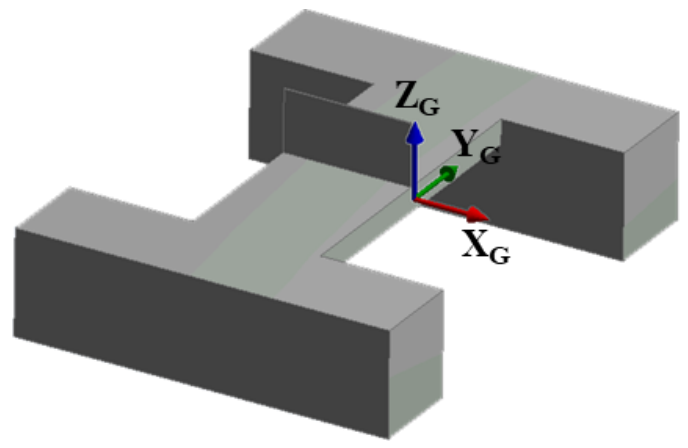

(a) The global axis

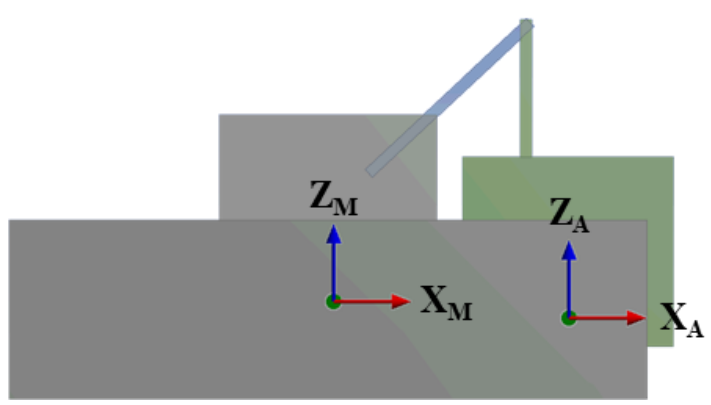

(b) The local axis of the main body and activating body

Fig. 2 Axis of simulations

Table 2 Principal hydrostatic results of the main body and the activating body

\begin{tabular}{|c|c|c|c|c|c|}
\hline Factor & $\begin{array}{c}\text { Center of Gravity } \\
(\mathrm{x}, \mathrm{y}, \mathrm{z})\end{array}$ & $\begin{array}{c}\text { Center of Buoyancy } \\
(\mathrm{x}, \mathrm{y}, \mathrm{z})\end{array}$ & $\mathrm{GM}_{\mathrm{T}}$ & $\mathrm{GM}_{\mathrm{L}}$ & Unit \\
\hline Main body & $-5.17,0,-2.859$ & $-5.17,0,-3.52$ & 36.31 & 9.48 & $\mathrm{~m}$ \\
\hline Activating body & $6.25,0,-3.64$ & $6.25,0,-2.50$ & 9.57 & 2.80 & $\mathrm{~m}$ \\
\hline
\end{tabular}

If the activating body was made up of a single material, its centroid of gravity would be too high. Thus, when the activating body faces a wave, the activating body would be overturned in simulations because its pitch motion became too high, and the activating body did not have enough strength of stability. To avoid this phenomenon, the centroid of gravity was lowered by installing a high-density mass in limited area from bottom to $40 \%$ of depth of activating body as shown in Figure 3 . This made the activating body stable for the pitch motion.

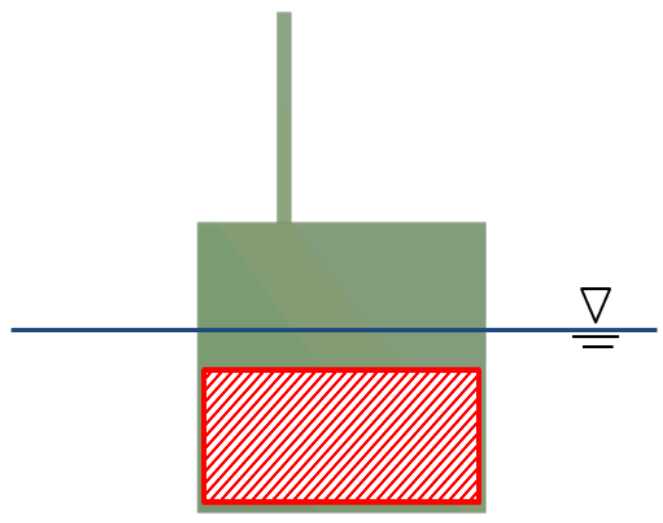

Figure. 3 Weighted area of the activating body 
The main body and the activating body were connected by connecting bridges and hinged or fixed connections to only allow heave and pitch motion between main body and activating body. As the relative motions between the main body and the activating body also affect the efficiency of power generation, translational motions and rotational motions of the main body were restrained by using four tensioned mooring lines.

\subsection{Connecting bridges}

Figure 4 shows the details of connecting bridges and activating body. "A" shows the distance between the location where connecting bridge was installed on the activating body and the edge of activating body, and red circles depict Joints 1, 2 and 3, respectively. "B" and "C" explains the length of connecting bridges. The dotted bar between Joint 3 and the centroid of gravity of activating $\operatorname{body}\left(G_{A}\right)$ is the imagined connection which will use to explain the relation between motion of the activating body and angular velocity of the joints. Joint 1 connected to the main body. By increasing the distance of " $A$ ", the length of "C" is also increased while the length of " $\mathrm{B}$ " is identical. In the present study, the simulations were conducted with six configurations (Table 3). In each configuration, the figure of "A" was changed, and the two connecting methods between " $\mathrm{B}$ " and " $\mathrm{C}$ " were also changed. The shape of the activating body was identical in all the configuration. Details of initial connection of the configurations are shown in dotted box of Figure 4.

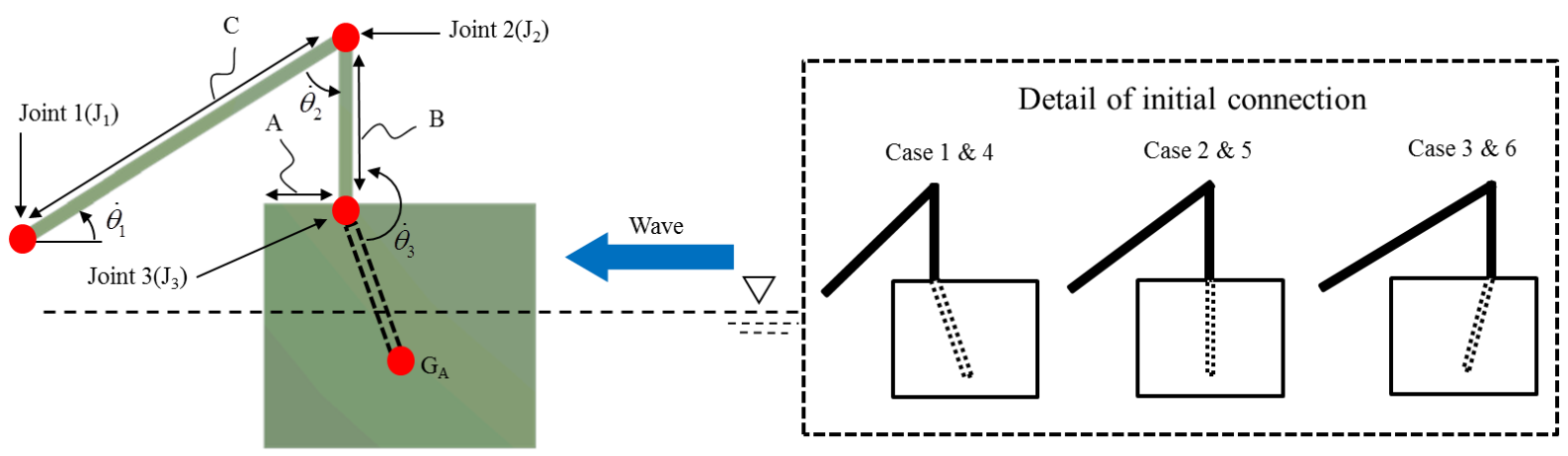

Fig. 4 Details of the connecting bridge and activating body

Relation between motion of the activating body and angular velocity of the joints could be expressed as follows.

$$
V_{G, r e l}=\dot{\theta_{1}} \vec{k} \times \vec{r}_{J_{2} / J_{1}}+\dot{\theta}_{2} \vec{k} \times \vec{r}_{J_{3} / J_{2}}+\dot{\theta}_{3} \vec{k} \times \vec{r}_{G_{A} / J_{3}}
$$

Where, $V_{G, r e l}$ is relative velocity of the activating body to the Joint $1, \vec{r}_{b / a}$ is relative position from the joint $\mathrm{b}$ to the joint $\mathrm{a}, \vec{k}$ is a unit vector.

The connecting methods consist of "Fixed" and "Hinged". "Fixed" restrains all kinds of motion of activating body while "Hinged" allows rotational motion of activating body, such as a pitch direction motion. The configurations of the connecting bridge used in the simulations are shown in Table 3. Therefore, the Eq.(1) can be modified as follows. When the join 3 is fixed, case 1, 2, and 3, the third term in the right hand side of eq.(1) is left out. On the other hand, when the joint 2 is fixed, case 4, 5, and 6, the second term is left out. This means that although a joint is suppressed, the other joints can be moved. As the two joints and the 
activating body simultaneously rotate and move, it is difficult to find out a direct effect of the motion of the activating body on the angular velocity of the joint 1 . It is assumed that the friction, stiffness, and damping effects of the joints are negligible.

Table 3 Configurations of the connecting bridge

\begin{tabular}{|c|c|c|c|c|c|}
\hline Case & $\mathrm{A}$ & $\mathrm{B}$ & $\mathrm{C}$ & Joint 2 & Joint 3 \\
\hline 1 & $3 \mathrm{~m}$ & $6.5 \mathrm{~m}$ & $10.5 \mathrm{~m}$ & Hinge & Fixed \\
\hline 2 & $5 \mathrm{~m}$ & $6.5 \mathrm{~m}$ & $12.1 \mathrm{~m}$ & Hinge & Fixed \\
\hline 3 & $7 \mathrm{~m}$ & $6.5 \mathrm{~m}$ & $13.8 \mathrm{~m}$ & Hinge & Fixed \\
\hline 4 & $3 \mathrm{~m}$ & $6.5 \mathrm{~m}$ & $10.5 \mathrm{~m}$ & Fixed & Hinge \\
\hline 5 & $5 \mathrm{~m}$ & $6.5 \mathrm{~m}$ & $12.1 \mathrm{~m}$ & Fixed & Hinge \\
\hline 6 & $7 \mathrm{~m}$ & $6.5 \mathrm{~m}$ & $13.8 \mathrm{~m}$ & Fixed & Hinge \\
\hline \multicolumn{7}{|c|}{ Remarks : Joint 1 locates at $\mathrm{x}=-3.15 \mathrm{~m}, \mathrm{y}=0 \mathrm{~m}, \mathrm{z}=3.3 \mathrm{~m}$ from the origin of global axis } \\
\hline
\end{tabular}

\subsection{Mooring lines}

Figure 5 depicts four mooring lines. The mooring system imitates the TLP(Tension Leg Platform) system and therefore the mooring lines were placed under the bottom surface of main body and moored the main body to the sea-bed. In order to prevent the main body from moving, such as translational and rotary motion, the group of mooring lines had pre-tension that accounts for about $23 \%$ of the main body's displacement[11]. Although the mooring lines relieve the motion of main body, it does not mean absolutely suppress. Therefore, the main body has slight translation and rotation motion which affect on power output. The mooring system was considered as a linear spring system. Therefore, mooring lines' stiffness $\left(K_{m}\right)$ were calculated by Eq.(2)

$$
K_{t}=K_{s}+K_{m}
$$

Where $K_{t}$ is the moored main body's stiffness, $K_{s}$ is the non-moored main body's stiffness. $K_{t}$ was calculated by nature frequency equation, Eq.(3)

$$
\begin{aligned}
& \omega_{h}=\frac{2 \pi}{T_{h}}=\sqrt{\frac{K_{t}}{m}} \\
& K_{t}=m\left(\frac{2 \pi}{T_{h}}\right)^{2}
\end{aligned}
$$


Where $\omega_{h}$ is a natural frequency of the moored main body for heave motion, $T_{h}$ is a natural period of the structure, and $m$ is a mass including added mass of the moored main body. In the TLP system, natural period of heave motion is considered less than $5 \mathrm{sec}$., and in this paper, natural period of heave motion was considered $2 \sec [11] . K_{s}$ based on water plane and was calculated by Eq.(4)

$$
K_{s}=\rho g A_{w}
$$

Where $\rho$ is the density of sea water, $g$ is the acceleration of gravity, and $A_{w}$ is the area of water plane.

Four mooring lines' properties and physical characteristics were shown in Table 4.

Table 4 Physical characteristics and mooring lines' properties

\begin{tabular}{|c|c|c|}
\hline Parameters & Symbol & Value \\
\hline Moored main body's stiffness & $K_{t}$ & $34,249,441 \mathrm{~N} / \mathrm{m}$ \\
\hline Non-moored main body's stiffness & $K_{s}$ & $7,179,448 \mathrm{~N} / \mathrm{m}$ \\
\hline Four mooring lines' stiffness & $K_{m}$ & $27,069,993 \mathrm{~N} / \mathrm{m}$ \\
\hline Natural period for heave motion & $T_{h}$ & $2 \mathrm{sec}$ \\
\hline Mass & $m$ & $3,470,194 \mathrm{~kg}$ \\
\hline Density & $\rho$ & $1025 \mathrm{~kg} / \mathrm{m}^{3}$ \\
\hline The acceleration of gravity & $g$ & $9.81 \mathrm{~m} / \mathrm{s}^{2}$ \\
\hline The area of water plane of main body & $A_{w}$ & $714 \mathrm{~m}^{2}$ \\
\hline
\end{tabular}

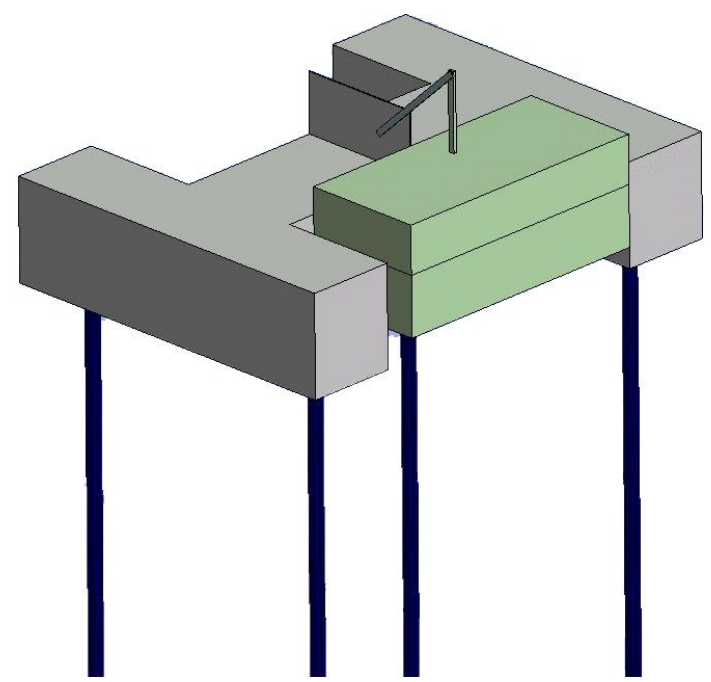

Fig. 5 Details of the mooring lines 


\section{Analysis of the wave-energy converter in regular waves}

The commercial simulation tool AQWA was used to carry out the motion simulation of the wave-energy converter. The AQWA is a widely used numerical tool and is capable of performing fully-coupled hydrodynamic assessment for various types of floating structures. A lot of studies have utilized the AQWA for a wide range of their applications to validate numerical dynamic analyses [12]. Wang et al. used the AQWA to investigate the maximum mooring tension of FPSO [13], and Kim et al. scrutinize design of the dual-buoy wave energy converter through the AQWA [10]. The assumption of AQWA is that the incident wave acting on the body is a harmonic wave and has a small amplitude compared to its length. Furthermore, in order to use potential flow theory, the fluid is assumed to be ideal, incompressible, and irrotational [14].

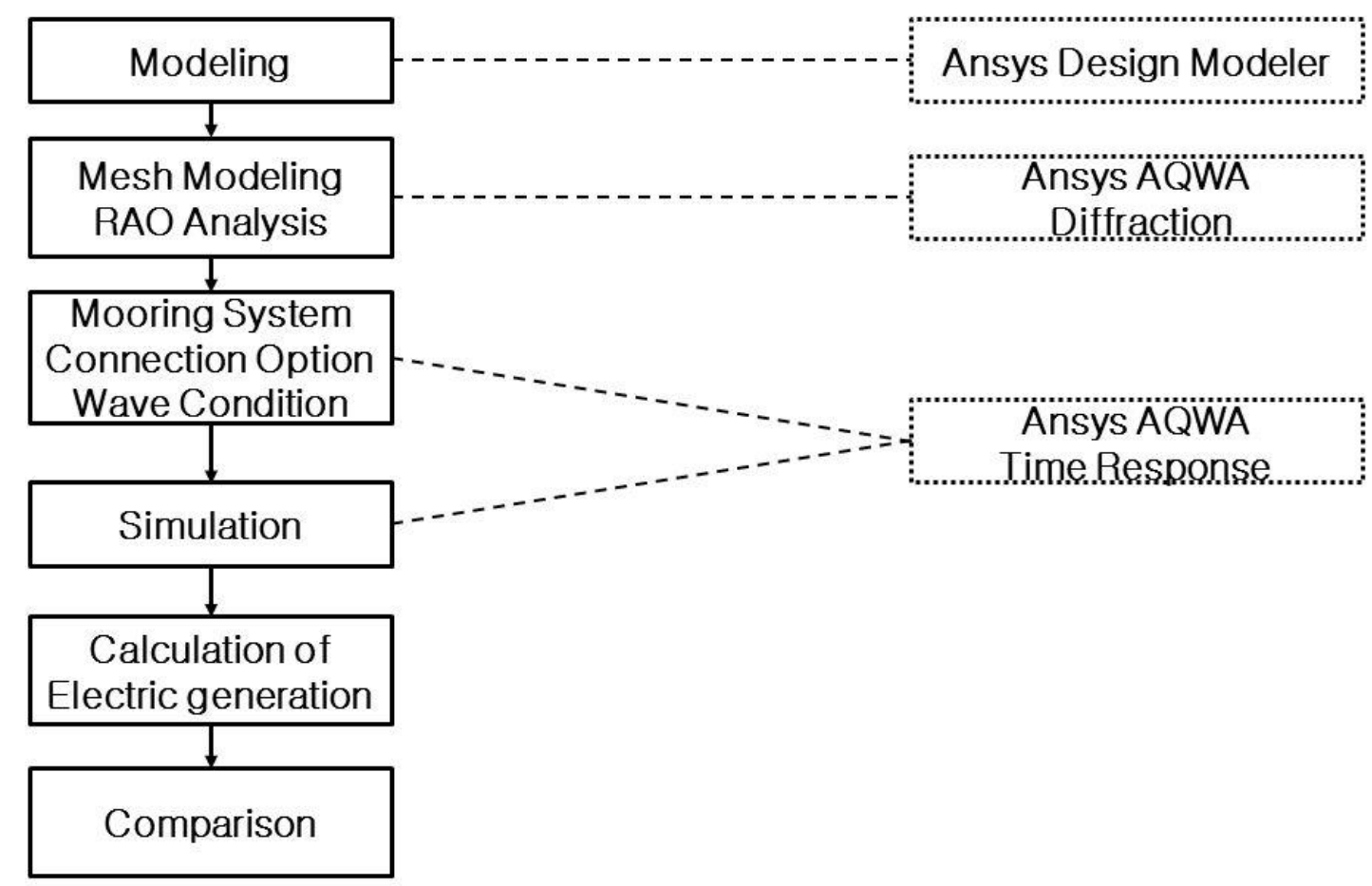

Fig. 6 Simulation process

Figure 6 shows the simulation process and the AQWA modules used in each process. Design Modeler was used in the modeling of the wave-energy converter. AQWA Diffraction was used to distribute meshes over the wave-energy converter and to calculate wave force on the meshes and the wave-energy converter.

\subsection{Mathematical model}

The wave force is divided into Froude-Krylov force, diffraction force, and radiation force and can be written as follows[15].

$$
F=\left[\left(F_{I}+F_{d}\right)+\sum_{k=1}^{6} F_{r k} x_{k}\right]
$$


Where, $F_{I}$ is the Froude-Krylov force, $F_{d}$ is the diffraction force, $F_{r}$ is the radiation force, and $k$ is degrees of freedom, from 1 to $6, x_{k}$ is translational and rotational motion of a center of gravity of the body. The Froude-Krylov force at a point $\vec{X}=[X, Y, Z]$ can be written as

$$
F_{I}=-i \omega \rho \int_{S_{0}} \varphi_{I}(\vec{X}) n d S
$$

Where, $\omega$ is a wave frequency, $\rho$ is density, $S_{0}$ is the mean wetted surface of the body, $\varphi_{I}$ is incident wave potential. Moreover, the diffraction force can be calculated as follows.

$$
F_{d}=-i \omega \rho \int_{S_{0}} \varphi_{d}(\vec{X}) n d S
$$

Where, $\varphi_{d}$ is diffraction wave potential. The radiation force can be explained as follows.

$$
F_{r k}=-i \omega \rho \int_{S_{0}} \varphi_{r k}(\vec{X}) n d S
$$

Where, $\varphi_{r k}$ is radiation wave potential induced by $k$-th motion. Therefore, the wave potential can be written as

$$
\varphi(\vec{X}) e^{-i \omega t}=\left[\left(\varphi_{I}+\varphi_{d}\right)+\sum_{j=1}^{6} \varphi_{r j} x_{j}\right] e^{-i \omega t}
$$

In the multiple structures case, hydrodynamic interaction is considerable. Therefore, the wave potential can be modified to consider hydrodynamic interaction as follows[15].

$$
\varphi(\vec{X}) e^{-i \omega t}=\left[\left(\varphi_{I}+\varphi_{d}\right)+\sum_{m=1}^{M} \sum_{j=1}^{6} \varphi_{r j m} x_{j m}\right] e^{-i \omega t}
$$

Where, $M$ is a number of structures. $\varphi_{r j m}$ is the radiation potential due to the unit $j$-th motion of the $m$-th structure while other structures remain stationary. Furthermore, 6-degree of freedom(DOF) rigid body motion can be explained as follow.

$$
\left(M_{s}+M_{a}\right) \ddot{x}+C \dot{x}+K x=F
$$

Where, $M_{s}$ is mass matrix of structure, $M_{a}$ is added mass matrix, $C$ is damping matrix, $K$ is stiffness matrix, $F$ is the wave force, and $x$ is response motions.

A sensitivity test was performed to determine the size of mesh. The test investigated the convergence of Response Amplitude Operator (RAO) of the activating body in the heave direction with maximum sizes of mesh witch were set $0.5 \mathrm{~m}, 1 \mathrm{~m}, 2 \mathrm{~m}, 3 \mathrm{~m}, 4 \mathrm{~m}$, and $5 \mathrm{~m}$. The 
results of the sensitivity test are shown in figure 7 . The figure 7 merely exhibits the peaks of RAO to see difference of RAOs well. When the maximum mesh size gets smaller, the variation among RAOs also gets smaller. Finally, the RAOs with the maximum mesh size $0.5 \mathrm{~m}$ and $1 \mathrm{~m}$ were almost similar. The discrepancy of areas of under RAO between the $0.5 \mathrm{~m}$ and $1 \mathrm{~m}$ was about $0.1 \%$. Therefore, $1 \mathrm{~m}$ maximum size of mesh was set to distribute mash over the activating body for the simulation. Figure 8 shows the distribution of the meshes on the wave-energy converter.

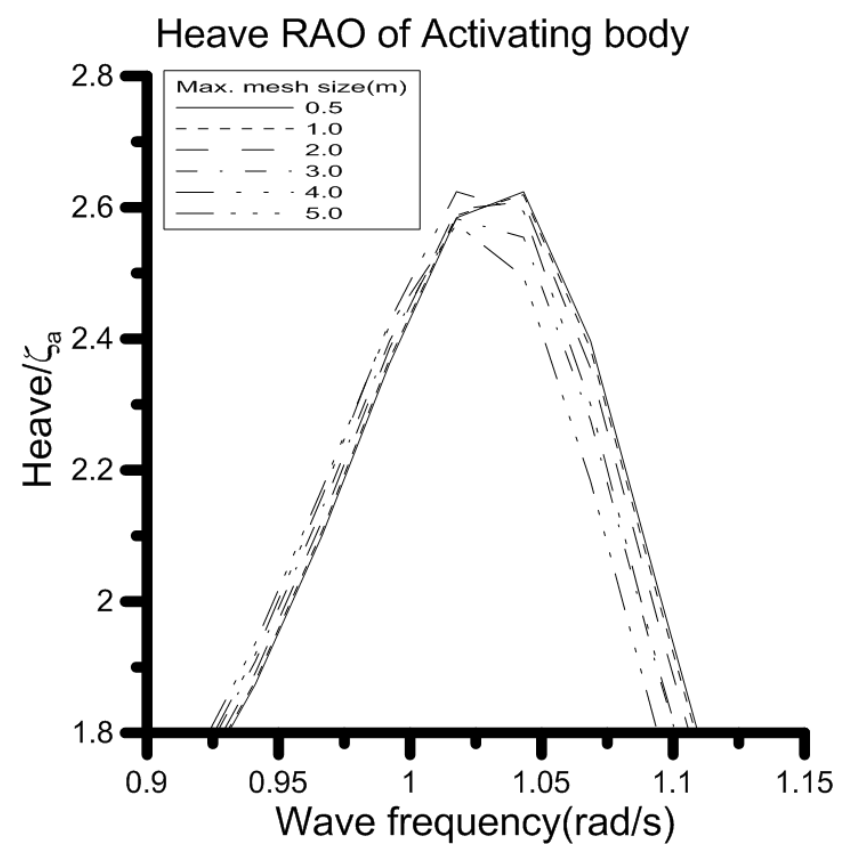

Fig. 7 Sensitivity test of mesh size with heave RAO of activating body

After the modeling, the motion RAO of the activating body was calculated with AQWA Diffraction, and the frequencies, which lead various heave motion respond, of regular waves for time-based simulations were selected based on the motion RAO. The mooring system for the wave-energy converter and the connection methods between the activating body and the main body were set in the AQWA Time response which was used for the time-based simulation. After the simulation, the angular velocity and the moment on Joint 1 were analyzed to calculate the power generation.

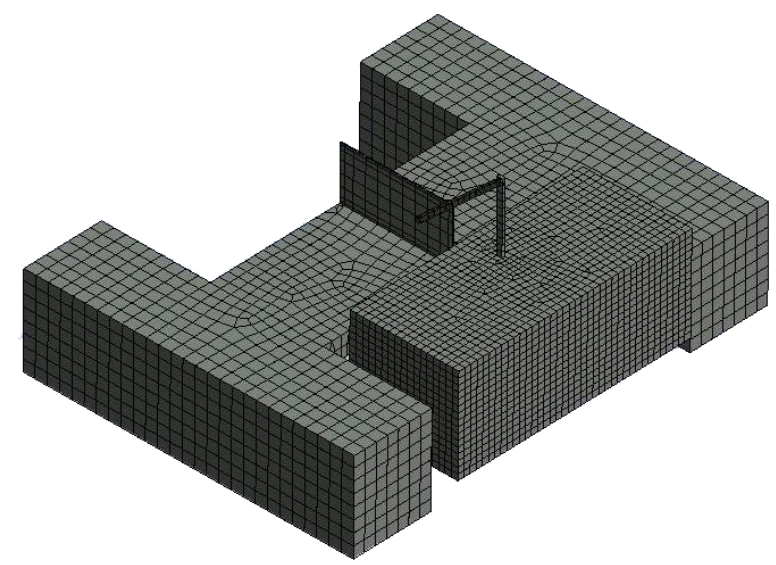

Fig. 8 Example of the mesh distribution on the wave-energy converter 


\subsection{Viscous effects}

As this analysis process is based on the potential theory, viscous effects are disregarded. Therefore, viscous damping elements, which are called disc and utilized to add viscous effects in AQWA[16, 17], were utilized. The disc's centroid is a point of action of viscous drag force, and summation of each four discs' area is equal to area of each numbered bottom surface[18]. The discs, which are displayed in the figure 9, were placed under the bottom surfaces, from one to four, and each surface had four discs. Each discs were assigned one quarter of the total area of the surface from one to four as shown in the right side of the figure 9, and a direction of all discs was vertical. The direction means a direction of viscous drag force. Finally, a viscous drag coefficient was set with 1.05 , and this value is equivalent to a common cube shape's viscous drag coefficient [19].

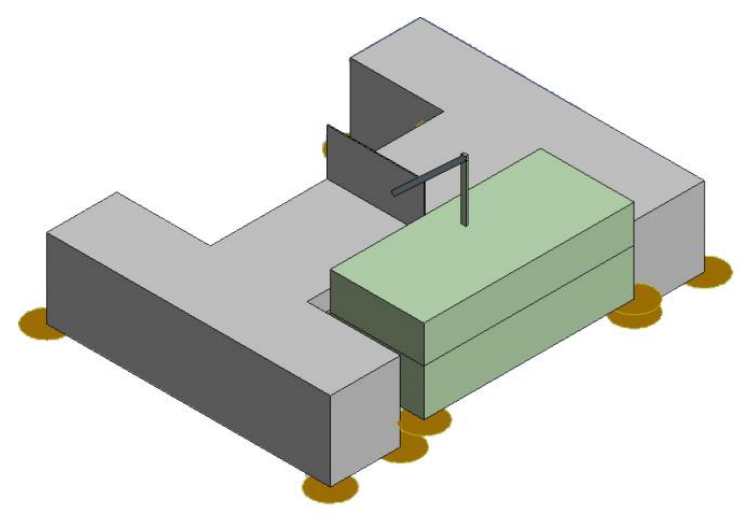

(a) Top view

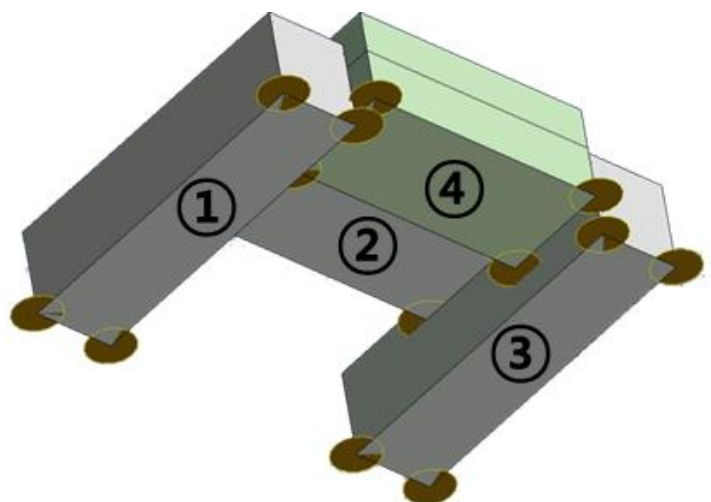

(b) Bottom view

Fig. 9 The viscous damping elements

\subsection{Wave conditions}

The wave conditions for the simulations were regular waves, the amplitudes were set to $1 \mathrm{~m}$ in all cases, as shown in Table 5, and the wave direction was set to $180^{\circ}$ in all cases, so that the waves faced the front of wave-energy converter. Four wave frequencies were selected based on the RAOs, which is shown in the figure 10, of the main body and activating body for the heave and pitch directions. $\varsigma_{a}$ and $k_{w}$, which were used to make non-dimension of RAOs in the Figure 10, are wave amplitude and wave number, respectively.

Table 5 Wave conditions in the simulations

\begin{tabular}{|c|c|c|c|}
\hline & Frequency & Wave length & Amplitude \\
\hline Wave 1 & $0.824 \mathrm{rad} / \mathrm{s}$ & $90.77 \mathrm{~m}$ & $1 \mathrm{~m}$ \\
\hline Wave 2 & $0.984 \mathrm{rad} / \mathrm{s}$ & $63.65 \mathrm{~m}$ & $1 \mathrm{~m}$ \\
\hline Wave 3 & $1.144 \mathrm{rad} / \mathrm{s}$ & $47.09 \mathrm{~m}$ & $1 \mathrm{~m}$ \\
\hline Wave 4 & $1.304 \mathrm{rad} / \mathrm{s}$ & $36.24 \mathrm{~m}$ & $1 \mathrm{~m}$ \\
\hline
\end{tabular}



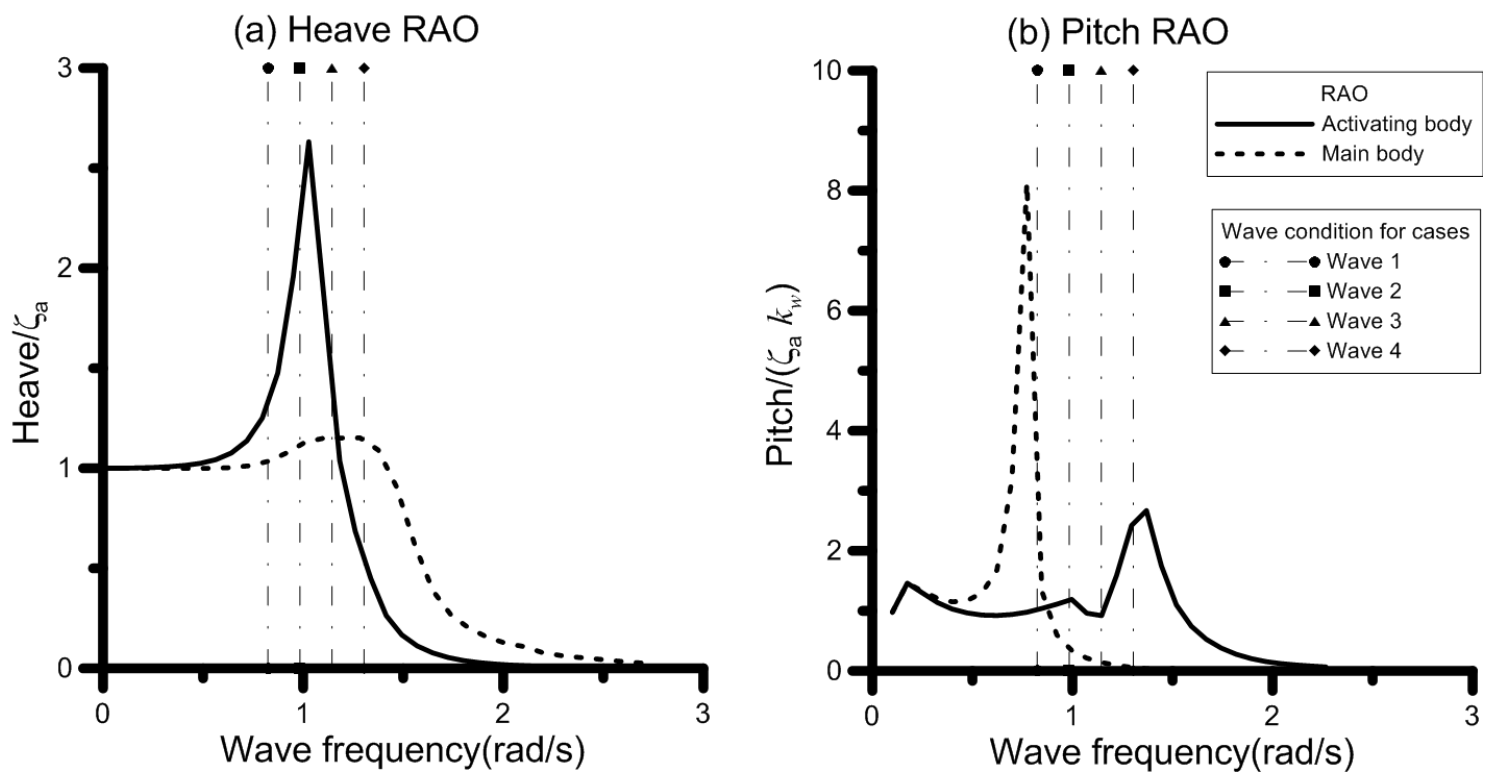

Fig. 10 Heave and Pitch RAOs of the main body and activating body

The selected waves have comparatively large wave length, which are shown in Table 5, in comparison with the length of activating body. However, high response motions of Heave and Pitch on both bodies were considered while selecting the wave frequencies. Moreover, the selected frequencies are slightly deviated from the frequencies which have the peak of RAOs to avoid resonance phenomenon.

\subsection{Calculation of the power output}

The WAB type wave-energy converter designed in this study exploits relative motions between the activating body and the main body. The relative motions are transferred to the joint 1 with the form of rotational energy through the other joints on the connecting bridges, and the rotational energy is used for power generation. The rotational energy is affected by both the activating body's surge, heave, and pitch motions and the main body's surge, heave, and pitch motions. The power output $\left(P_{G}\right)$ can be obtained by multiplying the moment and the angular velocity at Joint 1 . Thus, the power output as a result of the simulations was calculated through Eq. (12)[20].

$$
\mathrm{P}_{G}=\frac{1}{T} \int b \dot{\theta_{1}} d t(\mathrm{~kW})
$$

Where $T$ is total simulation time: $150 \mathrm{sec}$, $b$ refers to the moment in Joint 1 , which is hinge connected between the main body and the connecting bridge, and $\dot{\theta}_{1}$ refers to the angular velocity of the connecting bridge in Joint 1.

\subsection{Capture width}

In order to evaluate the performance of the wave energy converter, capture width was calculated through Eq. (13). It is a one of parameters that is used to measure the efficiency of a wave energy converter. Therefore, by using capture width, it is possible to decide that which setting is more useful and efficient[21]. As a capture width had length dimension, wave number was multiplied to change length dimension into dimensionless[22]. 


$$
C_{W}=\frac{\mathrm{P}_{G}}{\mathrm{P}_{W}}
$$

Where $C_{w}$ is capture width, $P_{G}$ is Power generated by the wave energy converter, and $P_{W}$ is the wave energy transport and calculated through Eq. (14).

$$
\mathrm{P}_{W}=\frac{1}{2} \rho g \varsigma_{a}^{2} C_{g}
$$

Where $\rho$ is the density of seawater, $\mathrm{g}$ is the acceleration of gravity, $\varsigma_{a}$ is the amplitude of wave, and $C_{g}$ is the group velocity of wave.

\section{Results of the simulations}

Connecting methods can be divided into the fixed or hinged connections in the connecting bridge on the activating body. The position of the connections can also differ. Figures 11-12 are parts of the simulations which would show the motion characteristics of the activating body when Joint 2 was hinged or when Joint 3 was hinged, respectively. The thick arrow in the front of the activating body indicates the direction of the incident waves, and the main body was fixed with mooring lines, which are shown under the main body.
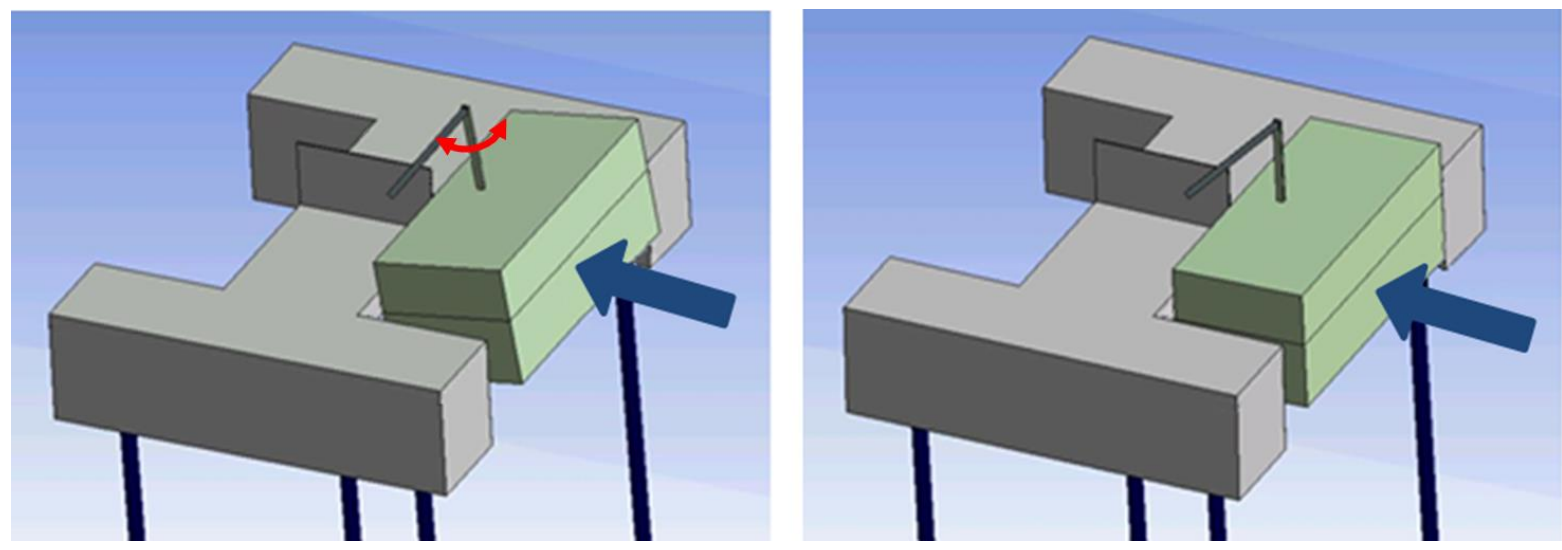

Fig. 11 Joint 2 hinged and joint 3 fixed
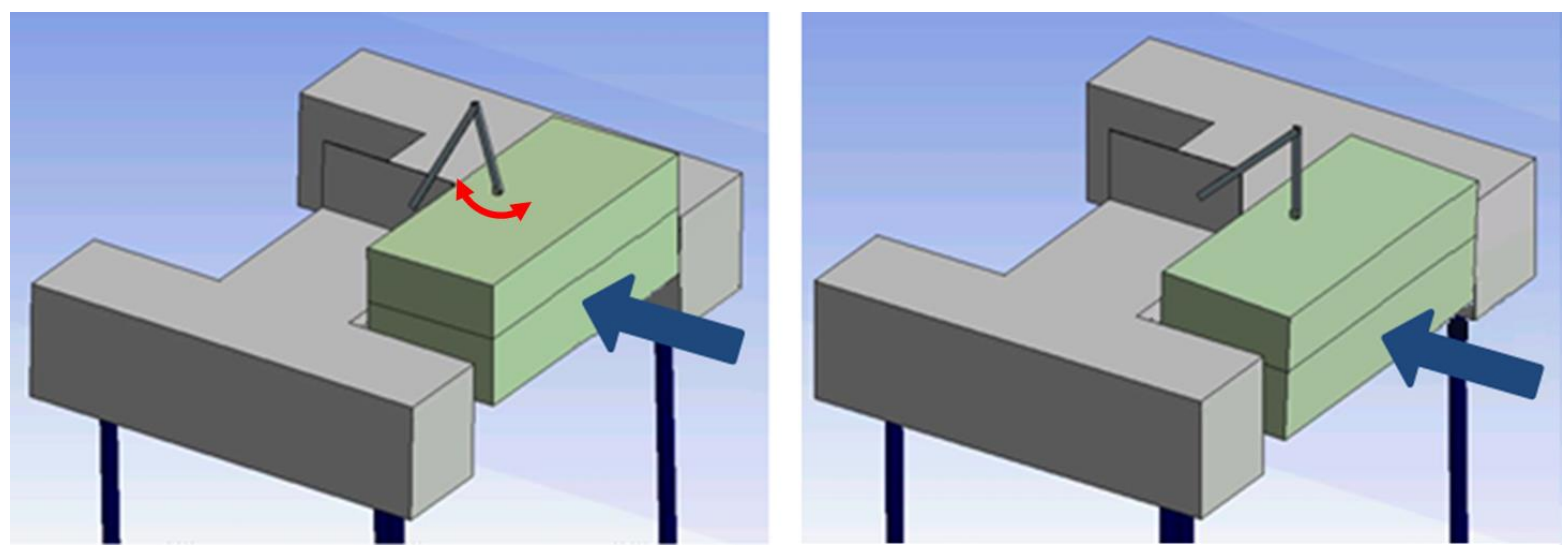

Fig. 12 Joint 2 fixed and joint 3 hinged 
Figure 11 shows the hinged connection at Joint 2 and the fixed connection at Joint 3. The activating body shows pendulum movements centering on Joint 2 , in addition to heave and pitch motions occurred because of the incident waves. These motions made the connecting bridge connected to the main body moved back and forth, thereby affecting the rotational motion on Joint 1 . Therefore, when Joint 2 was hinge connection, the pitch motions of the activating body affected the rotational motion of Joint 1 through the connecting bridges, thereby affecting the power generation. On the other hand, figure 12 shows the fixed connection at Joint 2 and the hinged connection at Joint 3. In this case, unlike the above case where the hinge connection was made at Joint 2, pendulum movements of the activating body centering on Joint 2 did not be occurred. Instead, pitch motions of the activating body mostly occurred at Joint 3. As a result, the pitch motions transferred to the main body through the connecting bridge were insignificant. However, the heave motions of the activating body were transferred to the main body through the connecting bridge. The simulation demonstrated that the pitch motions of the activating body had almost no effect on the rotational motions of Joint 1 unlike the case with the hinged connection at Joint 2.

In order to analyze a tendency of variation efficiency as the changes of connection methods and location, the amount of power generation, moment, angular velocity was measured. Figure 13 shows graphs of the power outputs calculated by Eq.(5). In other words, displayed power outputs are the average amount of power that is generated through simulation. Figure 13 (a) results from Joint 2 hinge option and (b) results form Joint 3 hinge option. The horizontal axis shows the changes in the distance of "A" (i.e., the location of the connecting bridge). The vertical axis shows the power outputs generated at Joint 1.

\section{(a) Power (Joint 2 hinge)}

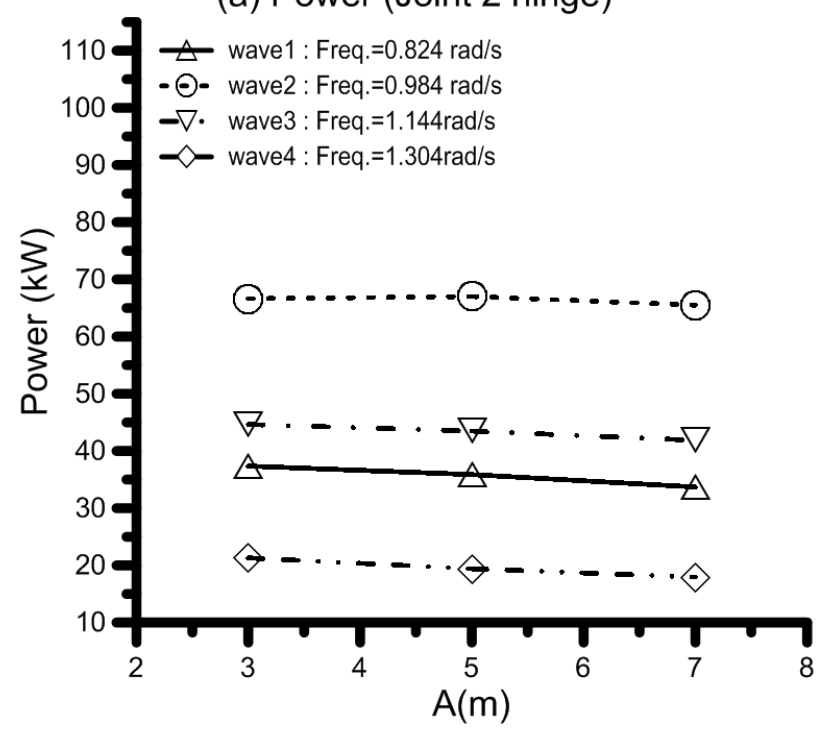

(b) Power (Joint 3 hinge)

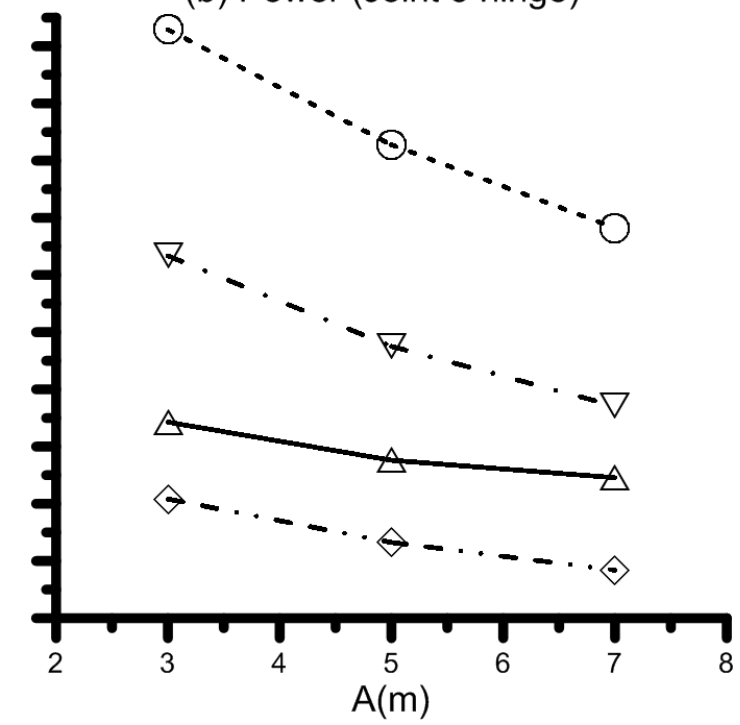

Fig. 13 Variation of the power output under the different types of the connections

As power generation was based on the movement of activating body and the wave conditions were based on the heave RAO of the activating body, it was expected that the largest amount of power was appeared under wave 2. As shown in the figure 13, the expectation was right. When joint 2 had the hinged connection(Figure 13 (a)), under all the wave conditions, the power outputs shows the tendency to descend as the values of "A", which is distance from the main body, ascends. This trend is also found when joint 3 had the hinged connection(Figure 13(b)). Additionally, the inclinations of Figure 13 (b) are sharper than those of Figure 13 (a). This meant that when joint 3 had the hinged connection, power 
outputs are more sensitive to variations of distance of A. Furthermore, under Joint 3 hinge option, the amount of generated power is larger than that of joint 2 hinge option and by using this result, the trend that in terms of power generation that joint 3 hinge option is much better than joint 2 hinge option could be found. To be specific, as shown above, if the joint 2 has a hinged connection, activating body takes pendulum motion and it affects the motion of joint 1. As a result, this effect was found as negative effect because all cases had low amount of power.

(a) Non-dimensional capture width (Joint 2 hinge)

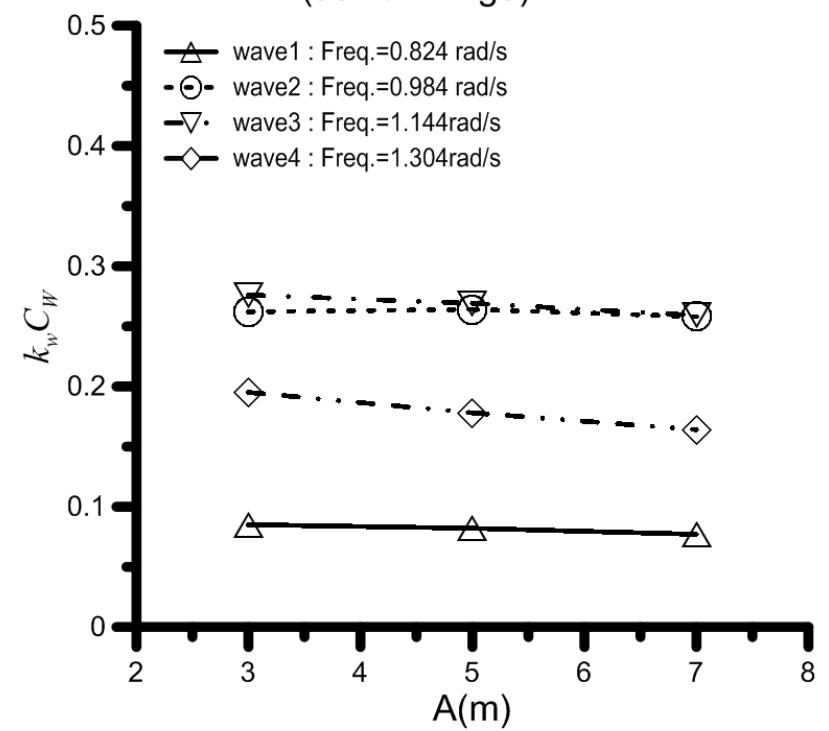

(b) Non-dimensional capture width (Joint 3 hinge)

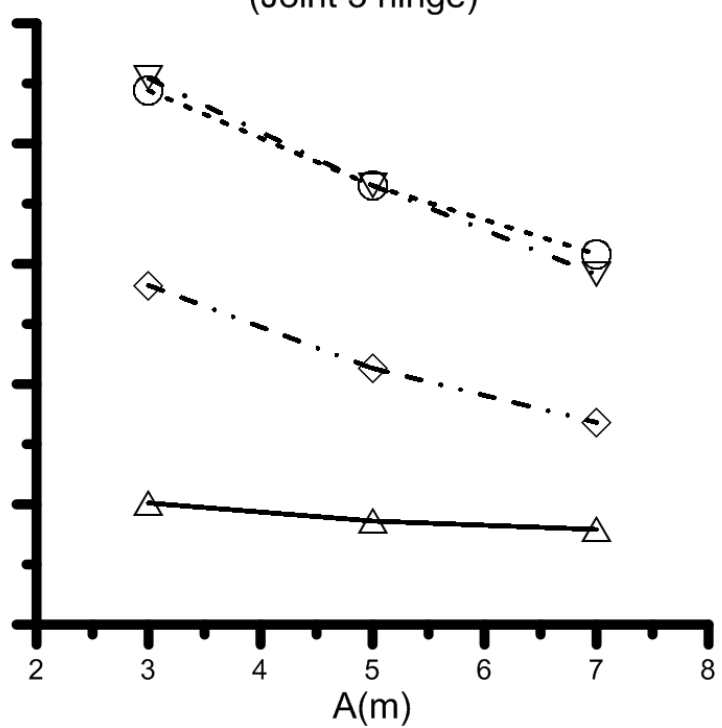

Fig. 14 Variation of the non-dimensional capture width under the different types of the connections

Figure 14 shows a non-dimensional capture width, which is calculated by multiplying $C_{W}$ in Eq. (6) and wave number $\left(k_{w}\right)$ together. The non-dimensional capture width is one of parameters to estimate the efficiency of a wave energy converter as mentioned above. The lowest wave frequency, wave 1 , become lower than the wave 4 because the wave 1 has the smallest wave number. This means that although the wave 4 generates the lower power, it has better efficiency than the wave 1. On the other hand, an important fact is that the same tendency of the power between joint 2 and 3 was found. Under joint 2 hinge condition, the variation of output power efficiency is low but under joint 3 hinge condition, the range of variation is relatively large. Therefore, it is appropriate to say that when joint 3 had a hinged connection, power efficiency is better and more sensitive to distance of A.

Since the power is calculated through Eq.(12), it is needed to consider moment of the joint 1 to scrutinize the tendency of power. Therefore, figure 15 explains moment that was measured at the joint 1 . The vertical axis means average RMS(root mean square) moment and other values are the same those of the power graphs in figure 13. In the case of power graphs, all cases descend when the values of $\mathrm{A}$ ascend but in view of moment, there is a different trend that if the joint 2 has the hinged connection, moment ascends as the A's distance ascends. In addition to the change of the A distance, the change of wave frequency also lead to a dissimilar result. If the joint 2 has the hinged connection, the wave frequency has no significant effect on the moment. On the other hand, when the joint 3 has a hinged connection, the variation tendency is similar with the variation tendency of power with the joint 3 hinged case. 
(a) Moment (Joint 2 hinge)

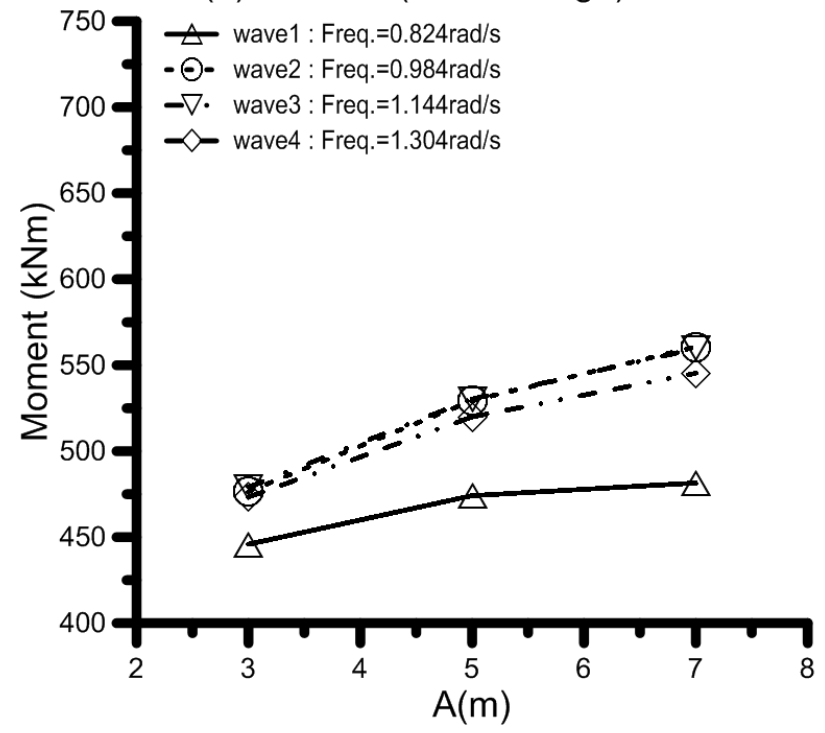

(b) Moment (Joint 3 hinge)

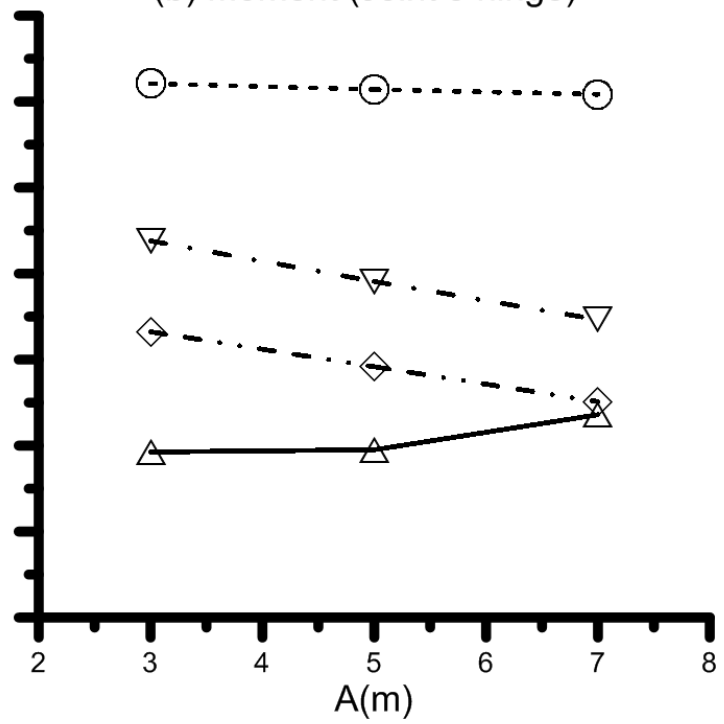

Fig. 15 Variation of the moment under the different types of the connections

Since the moment was calculated by the length of moment arm and force, and the force is calculated by mass and acceleration, the angular acceleration at joint 1 is needed to investigate these trends. Time domain graphs of, which depict absolute-values of angular acceleration of the joint 1 under the wave 3 condition, are shown at Figure 16. The graphs explain merely specific simulation time from $120 \mathrm{sec}$. to $150 \mathrm{sec}$. to show the trends clearly because if the graphs depict from zero sec., they are too broad to find out variation of data. Thus, the figures (a) and (b) are enlarged from 0.2 to $0.45 \mathrm{rad} / \mathrm{s}^{2}$ and from 135 to $150 \mathrm{sec}$. in the right side of the figure.

(a) Angular Acceleration (Joint 2 hinge)

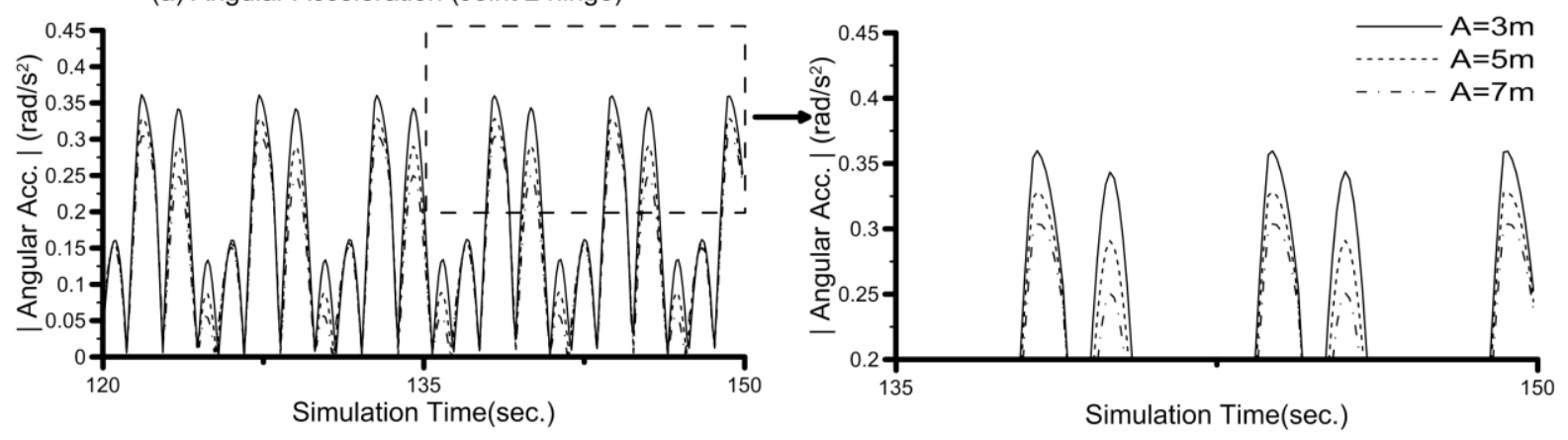

(b) Angular Acceleration (Joint 3 hinge)

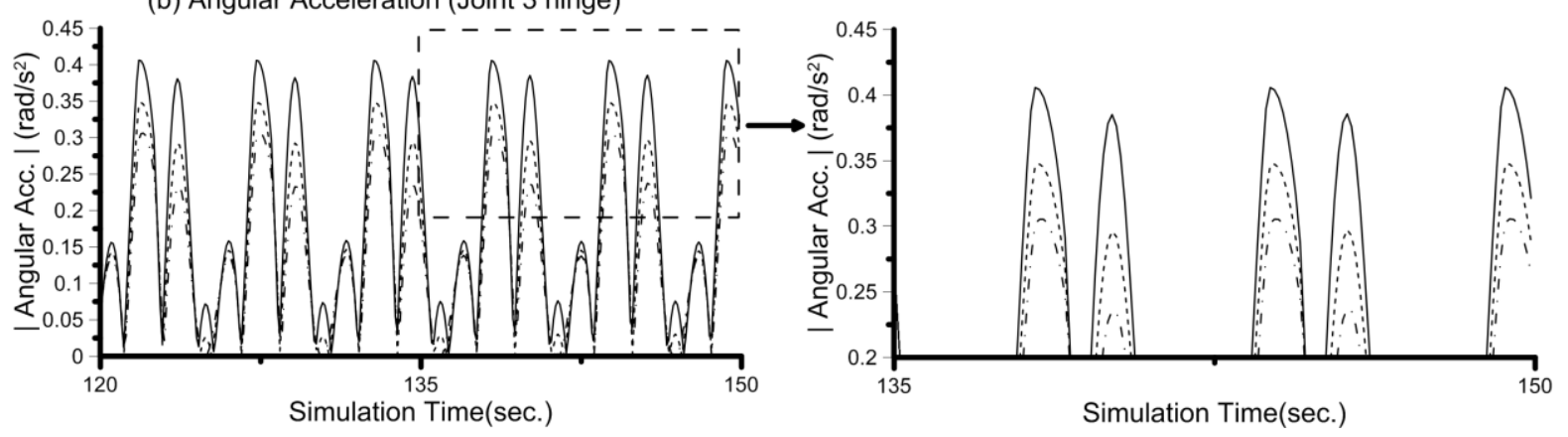

Fig. 16 Angular acceleration under the wave 3 
There are some variations of amplitude throughout the simulation time because the angular acceleration considers the relative motion between the main body and the activating body. In other words, the small amplitude explains that both the activating body and the main body move in one direction. On the other hand, the big amplitude explains that they move in different direction. According to the (a) graph that shows results when joint 2 hinge option, there are a few variation. Therefore, it is natural that the moment figure is ascended as the figure of $\mathrm{A}$ is ascended. This is because similar acceleration means that the figure of moment is determined by the length of moment arm. However, in the case of joint 3 hinge option, there is relatively large variation and this bring that even though the length of moment arm gets longer, the figure of moment gets smaller because of descending force.

(a) Angular Velocity (Joint 2 hinge)

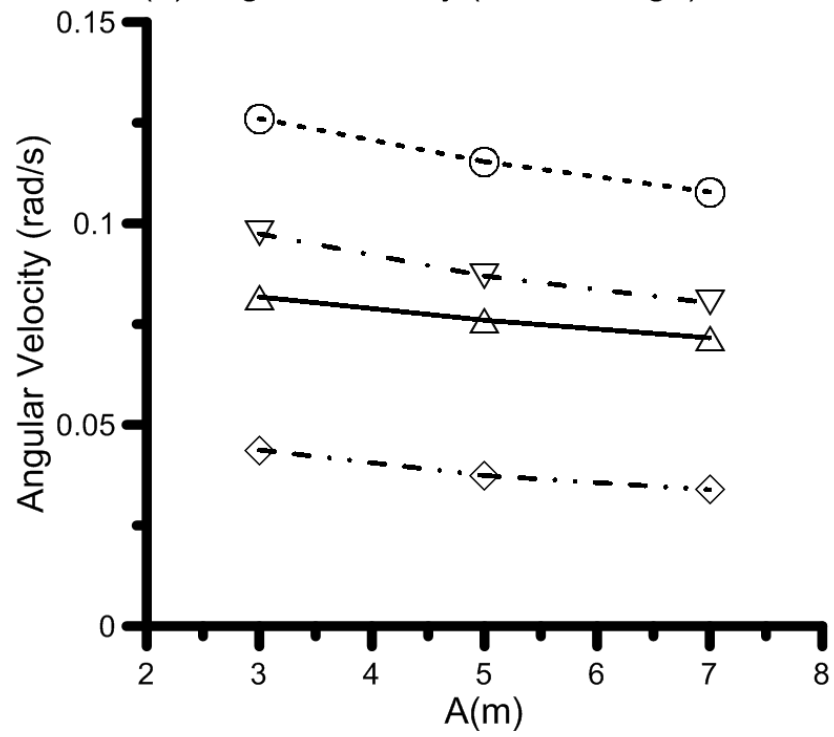

(b) Angular Velocity (Joint 3 hinge)

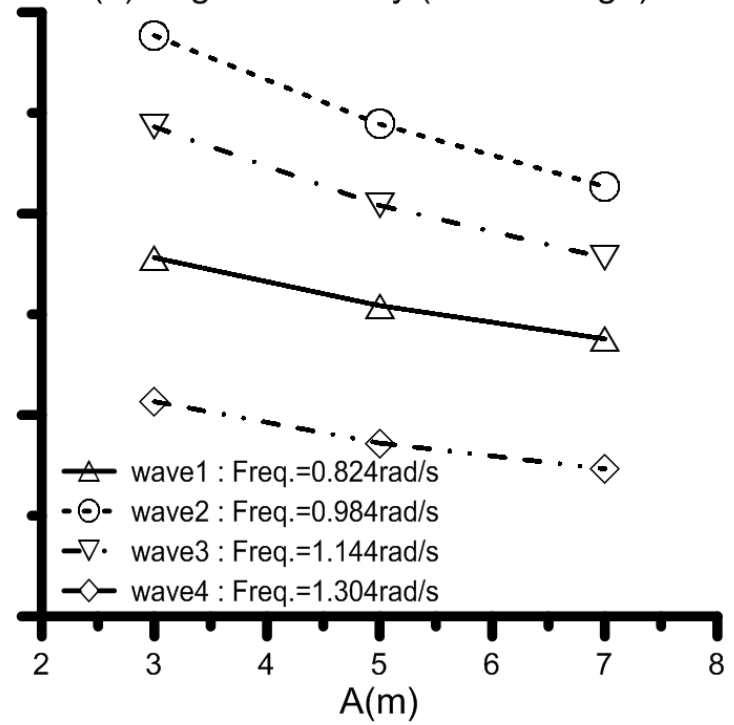

Fig. 17 Variation of the angular velocity under the different types of the connections

As mentioned above, as angular velocity is one of the main factors to calculate the power, the angular velocity is shown in figure 17 to be investigated. The vertical axis means average RMS angular velocity and other values are same those of power graphs. The angular velocity descends as the value of the A ascends, as depicted in the figure 17 (a) and (b). There is no prominent tendency but the similar tendency of power generation. The only difference is that the contrast between the joint 2 hinge and the joint 3 hinge is pretty little. Thus, it is found out that the angular velocity would not be affected by the connecting method as much as moment received. Moreover, a figure 18 shows the relative velocities between the main body and activating body. These velocities are the factors of the angular velocity at the joint 1 as mentioned above the figure 17. Time histories of velocities are compared between the case 1(Joint 2 hinged) and case 4(joint 3 hinged) which have that the $\mathrm{A}$ is $3 \mathrm{~m}$ and the wave condition is $2($ Freq. $=0.984 \mathrm{rad} / \mathrm{s})$. There is no discrepancy of heave velocity between the two bodies, while the surge velocity of the case 4 has comparatively the larger value. This is because the case 4 has the fixed Joint 2 . When the joint 2 is fixed, the sure motion of activating body can easily affect the joint 1 through the connection bridge $\mathrm{B}$ and $\mathrm{C}$ because the surge motion can push both the connection bridge B and C. However, in the case 1, joint 2 hinged and joint 3 fixed, the surge motion leads a swing based on the joint 2, and the swing reduces the effect of sure motion on the joint 1 because the kinetic energy caused by the surge motion is relieved by the swing. In other words, the surge motion of activating body of case 4 has a direct influence on the angular velocity of the joint 1 as compared with that of case 1 . 
This difference is one of the reasons that the cases with the hinged Joint 3 in the figure 17 have the larger angular velocities. In contrast, in the case of the pitch motion, the case 1 is faster than the case 4 . The reasons are that if the joint 2 is hinged and the joint 3 is fixed, the case 1 , the pitch motion of the activating body easily affect the joint 1 through the connection bridge $\mathrm{B}$ and $\mathrm{C}$ because the pitch motion activating body must move with the connection bridge $\mathrm{B}$, thereby being able to push the bridge $\mathrm{C}$. Additionally, if the joint 2 is fixed and the joint 3 is hinged, the case 4 , the pitch motion is occurred as a swing base on the joint 3 . This means that the effect of pitch motion on the joint 1 is less than that of the case 1 . Nevertheless, since the variation of pitch motion between the case 1 and 4 is much smaller than the variation of surge motion, the figure 17 is reasonable.
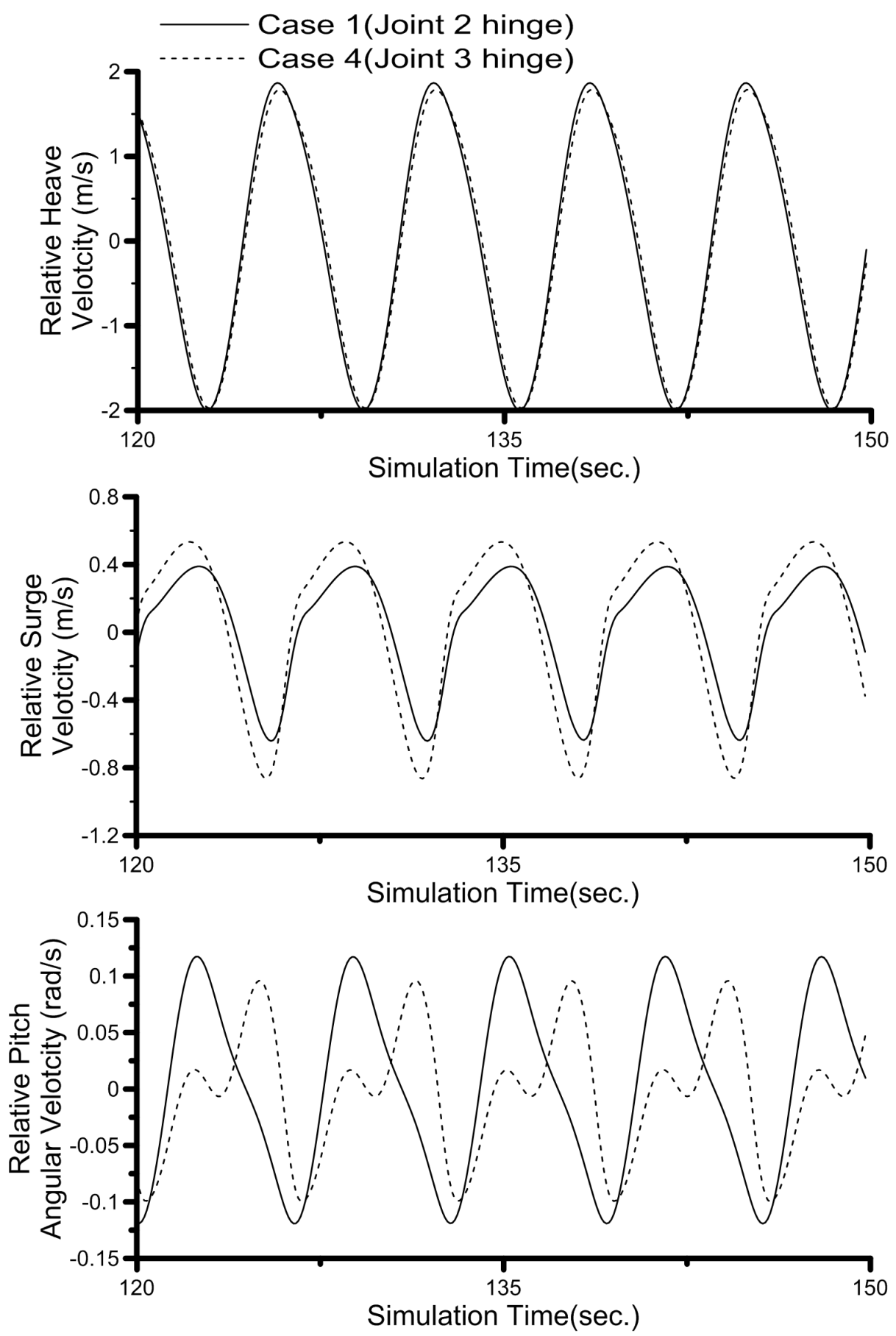

Fig. 18 Relative velocities between the main body and activating body at the wave 2 


\section{Conclusion}

In the present study, to examine the motion characteristics of an activating body of a WAB- type wave-energy converter according to changes in connecting methods, wave-energy converters were modeled with a commercial software, AQWA, and simulations were conducted. The power outputs were calculated from the moments and angular velocities obtained from the results of the simulations, and the results were analyzed. The conclusions obtained from the present study were as follows:

In the case of wave-power generation systems that use the heaves and pitches of the activating body for power generation, the power generation can be improved by a type of connections, which suppress the effect of the pitch motions of an activating body(i.e. joint 3 have hinged connection.). Changing the location of the connecting bridge also has an effect on the power generation. In this study, as the power is calculated by moment and angular velocity, the longer the distance of connection location is, the less power is generated. However, in specific cases, this is not prominent. For example, if there is a generator that do not significantly consider angular velocity and it cannot suppress the effect of the pitch motions of an activating body, the longer the distance of connection location is, the more power is generated. On the other hand, if an angular velocity is a dominant factor for energy generation, the distance of connection location is pretty important because in this case, a connection type have a few effect on angular velocity.

Future work are noted as follows. As the wave conditions considered in this study are merely regular waves, the wave conditions vary from real sea site conditions. Therefore, irregular wave conditions should be considered. The effectiveness of wave-energy converter should be also investigated by considering the conditions of installation site such as irregular wave and gust wind and so on. Furthermore, the optimization of shape of the activating body and the main body should be conducted.

\section{ACKNOWLEDGMENTS}

This research was supported by Basic Science Research Program through the National Research Foundation of Korea(NRF) funded by the Ministry of Education (2017R1D1A3B03 028250).

\section{REFERENCES}

[1] Yueh, C.Y. and Chuang, S.H., (2013). A Piston-Type Porous Wave Energy Converter Theory. Journal of Marine Science and Technology 21, 309-317. doi : 10.6119/JMST-012-0518-1.

[2] Chen, D.W., Tzang, S.Y., Hsieh, C.M., Chow, Y.C., Chen, J.H., Lin, C.C. and Hwang, R.R., (2014). Numerical Modeling of Wave-induced Rotations of a Bottom-hinged Flapper with a SPH Model. Journal of Marine Science and Technology 22, 372-380. doi : 10.6119/JMST-012-1221-1.

[3] Hong, K.Y., Shin, S.H., Hyun, B.S., Ryu, H.J., Park, S.J. and Moon, J.S., (2007). Oscillating Flow Field Analysis as Shape of Air Chamber in OWC-type Wave Energy Conversion. Journal of Navigation and port research 31, 29-33. (in Korean, with English Abstract) doi : 10.5394/KINPR.2007.31.1.029. https://doi.org/10.5394/KINPR.2007.31.1.029.

[4] Lee, K.H., Park, J.H., Baek, D.J., Cho, S. and Kim, D.S., (2011). Discussion on Optimal Shape for Wave Power Converter Using Oscillating Water Column. Journal of Korean Society of Coastal and Ocean Engineers 23, 345-357. (in Korean, with English Abstract) doi : 10.9765/KSCOE.2011.23.5.345. https://doi.org/10.9765/KSCOE.2011.23.5.345.

[5] Shin, S.H. and Hong, K.Y., (2006). An Experimental Study of Wave Overtopping Characteristics on the Structure for Wave Overtopping Power Generating System. Journal of navigation and port research 30, 
649-655. (in Korean, with English Abstract) doi : 10.5394/KINPR.2006.30.8.649. https://doi.org/10.5394/KINPR.2006.30.8.649.

[6] Cho, B., Yang, D., Park, S., Choi, K. and Park, B., (2011). Design of a 50kW Class Rotating Body Type Highly Efficient Wave Energy Converter. Trans. of the Korean Hydrogen and New Energy Society 22, 552-558. (in Korean, with English Abstract).

[7] Nam, B. W., Hong, S. Y., Kim, K. B., Park, J. Y. and Shin, S. H., (2011). Numerical Analysis of Waveinduced Motion of Floating Pendulor Wave Energy Converter. Journal of Ocean Engineering and Technology 48, 28-35. (in Korean, with English Abstract) doi : 10.5574/KSOE.2011.25.4.028. https://doi.org/10.5574/KSOE.2011.25.4.028.

[8] Carlos, G. S., Joydip, B. and Debabrata, K., (2014). Overview and Prospects for Development of Wave and Offshore Wind Energy. Brodogradnja /Shipbuilding, Vol.65, no.2, pp87-109.

[9] Hassan A., M. Rafiqul I., Adi M., Amin M. and Jaswar K., (2016). Experimental Study of Motions of Two Floating Offshore Structures in Waves. Brodogradnja/ Shipbuilding, Vol. 67, no.2, pp1-13 doi: 10.21278/brod67201. https://doi.org/10.21278/brod67201.

[10] Kim, J.R., Kweon, H.M., Jeong, W.M., Cho, I. H. and Cho, H. Y., (2015). Design of the dual-buoy wave energy converter based on actual wave data of East Sea. International Journal of Naval Architecture and Ocean Engineering 7(4), 739-749 doi :10.1515/ijnaoe-2015-0052. https://doi.org/10.1515/ijnaoe-2015$\underline{0052 .}$.

[11] Choi, H. S., Park, R. S. and Jo, C. H., (2001). Mega-Float Offshore Structure. Daesun, Seoul.

[12] Singhal, G., Mao, M., Croston, A. and Daly, E., (2013). Motion and Riser Design Feasibility Study for a Specialized Ship Conversion Using Commercial Software. Proceedings of the $23^{\text {th }}$ International Offshore and Polar EngineeringAnchorage, Alaska, USA, pp71-78.

[13] Wang, H., Ma, G., Sun, L., and Hu, K., (2017). Model Test and Coupled Dynamic Analysis of A Deepwater FPSO with Internal Turret Mooring System. Brodogradnja/ Shipbuilding, Vol. 68, no.4, pp4355 doi: 10.21278/brod68403. https://doi.org/10.21278/brod68403.

[14] Ansys, (2012). AQWA ${ }^{\mathrm{TM}}-$ LINE manual release 14.5, USA.

[15] Ansys, (2015). Aqwa Theory Manual release 16.0, USA.

[16] Sow, C.L., Koto, J. and Abyn, H., (2014). Semi-Submersible Heave Response Study Using Diffraction Potential Theory with Viscous Damping Correction. Journal of Ocean, Mechanical and Aerospace Science and Engineering, Vol. 5.

[17] Bhinder, M. A., Karimirad, M. and Weller, S., (2015). Modelling mooring line non-linearities (material and geometric effects) for a wave energy converter using AQWA, SIMA and Orcaflex. Proceedings of the $11^{\text {th }}$ Ertopean Wave and Tidal Energy Conference, Nantes, France, pp 6-11.

[18] Ansys, (2012). Aqwa User Manual release 14.5, USA.

[19] Hoerner, S.F., (1965). Fluid-dynamic drag. Great Britain, New York.

[20] Yeung, R. W., Peiffer, A., Tom, N. and MatlakDesign, T., (2011). Analysis, and Evaluation of the UCBerkeley Wave-Energy Extractor. Journal of Offshore Mechanics and Arctic Engineering 134. 021902. doi:10.1115/1.4004518. https://doi.org/10.1115/1.4004518.

[21] Garnaud, X. and Mei C. C., (2009). Wave-power extraction by a compact array of buoys. Journal of Fluid Mechanics, Cambridge University Press (CUP), vol 635, pp 389-413. https://doi.org/10.1017/S0022112009007411.

[22] Choi, Y. R., (2011). Estimation of Wave Energy Extraction Efficiency for a Compact Array System of Small Buoys. Journal of Ocean Engineering and Technology 23(1), 2, 8-13 doi : 10.5574/KSOE.2011.25.1.008. https://doi.org/10.5574/KSOE.2011.25.1.008.

Submitted: 13.04.2017. Sung-Soo Kim Jong-Hyun Lee

Accepted: 21.12.2017. Soon-Sup Lee

Donghoon Kang, kangdonghoon@gnu.ac.kr

Department of Ocean System Engineering, Gyeongsang National University, Korea Seung Jae Lee

Division of Naval Architecture and Ocean System Engineering, Korea Maritime University, Korea 